\title{
Os diferentes interesses nas Operações de Paz: casos Canadense e Brasileiro
}

The different interests in Peacekeeping Operations: Canadian and Brazilian cases

Beatriz Martins de Albuquerque ${ }^{1}$

Jéssica Pires Barbosa Barreto²

DOI: $\underline{10.5752 / \mathrm{P} .1809-6182.2019 \mathrm{v} 16 . \mathrm{n} 1 . \mathrm{p} 10}$

\begin{abstract}
Resumo
Apesar do discurso humanitário envolvendo as Operaçôes de Paz da Organização das Naçôes Unidas, Estados possuem interesses que vão além dessa conotação de ajuda coletiva. Assim, o artigo analisa de que forma paises usam as operaçóes para seus próprios objetivos, como plataforma para projeção, observando os casos canadense e brasileiro.
\end{abstract}

Palavras-chave: Operaçóes; Brasil; Canadá

\begin{abstract}
Despite the humanitarian discourse surrounding United Nations Peacekeeping operations, states have interests that go beyond this connotation of collective aid. Thus, the article analyzes how countries use the operations for their own purposes, as a platform for projection for example, observing the Canadian and Brazilian cases.

Keywords: Peacekeeping; Brazil; Canada
\end{abstract}

\footnotetext{
1 Mestranda em Estudos Estratégicos pelo Programa de Pós-Graduação da Universidade Federal Fluminense (PPGEST/UFF). Bacharel em Relaçóes Internacionais pelo Instituto de Estudos Estratégicos da Universidade Federal Fluminense (INEST-UFF). São Gonçalo (RJ)/Brasil. ORCID: 0000-0001-5029-1908. (D)

2 Mestranda em Estudos Marítimos pelo Programa de Pós-Graduação em Estudos Marítimos da Escola de Guerra Naval (PPGEM/ EGN) e em Estudos Estratégicos pelo Programa de Pós-Graduação da Universidade Federal Fluminense (PPGEST/UFF). Bacharel em Relaçóes Internacionais pela Universidade do Estado do Rio de Janeiro (RI/UERJ). Email: barretojessicapb@gmail.com. Rio de Janeiro/ Brasil. ORCID: 0000-0002-1176-3682. (D)
} 


\section{Introdução}

As operaçóes de paz se configuram dentro do âmbito da Organização das Naçóes Unidas (ONU) como um esforço coletivo para ajudar na resolução de disputas em áreas de conflito por um meio pacífico. Entretanto, muitos Estados apresentam interesses que vão além da consciência humanitária para participarem dessas operaçóes. Envolvendo forças militares de diferentes Estados, diversos países que não possuem proeminência internacional enxergam sua participação positiva nessas operaçôes como uma possibilidade de projeção internacional.

A Teoria Realista Neoclássica surge, segundo Taliaferro et al (2016), como um esforço para fugir do grau de determinismo imposto pelo Neorrealismo, apontando que a distribuiçấo de poder relativo dentro do sistema internacional, que é anárquico, é importante, mas não deve ser vista independente das variáveis internas dos Estado, sendo uma delas forma como os líderes percebem as informaçôes e os imperativos do sistema. Assim, "escolhas políticas não são mais concebidas como um produto direto de estímulos sistêmicos; em vez disso, eles passam pelo prisma do estado, que os percebe e responde a eles dentro dos limites institucionais de suas circunstâncias domésticas singulares" (TALIAFERRO et al, 2016, p. 31, traduçâo nossa).

Dessa forma, como apontado também por Wohlforth (1993), essa percepção sobre o sistema e sua distribuição de poder afeta o comportamento dos Estados tanto quanto a distribuição em si. Nesse sentido, observamos a percepção de Potência Média influenciando as estratégias e objetivos de um país. Sendo definido como um Estado que não é uma superpotência, mas possui a capacidade de exercer influência no sistema internacional, muitas vezes ditando a agenda de segurança do momento, as potências médias encontram em organizaçóes internacionais os melhores espaços para projeção de valores, não correndo o risco de serem taxados de imperialistas nem de perderem seus benefícios de segurança em relação a grandes poderes (KEATING, 2002).

As operaçóes de paz se tornaram a partir dos anos 1990, uma das principais vertentes de atuação da ONU para cumprir o seu objetivo primeiro, ou seja, manter a segurança e a paz no âmbito internacional através de medidas tomadas coletivamente (ONU, 1945). Segundo o Department of Peacekeeping Operations (DPKO), esta atividade tem como objetivo prover segurança e suporte político para a construção da paz a países em transição do conflito para a paz (UN PEACEKEEPING, 2018?). Apesar do discurso de caráter humanitário, Priscila L. F. Faganello (2013) aponta que as passaram a atrair um número maior de países interessados em contribuir, especialmente de potências medias em busca de uma maior relevância dentro do sistema ONU, inclusive mostrando a multiplicidade de atores presentes no quadro de "pacificadores".

Dessa forma, vê-se que a análise das operações de paz com o viés de projeção de poder é importante para entender os esforços dos países em volta dessas situaçôes. Para tanto, Brasil e Canadá são exemplos dessa participaçáo, fazendo parte dessas operaçóes com destaque desde o início da organização. Através de seus documentos oficiais, percebe-se que ambos se auto denominam "potência média", inclusive usando esse status para determinar os objetivos nacionais que identificam como coerentes para uma potência intermediária. Desde a Política de Defesa de 1964, o Canadá usa o termo para se caracterizar, mantendo essa prática inclusive para justificar sua falta de capacidade.

Outro ponto em comum nas duas potências médias é a colaboração para a estabilidade do sistema internacional, visto que essa condiçâo estabelece melhores possibilidade de prosperidade para tais Estados, como aponta Gelson Fonseca Junior (1998a), "Como país médio, interessa-nos que exis- 
tam regimes estáveis, que permitam incorporar o maior número de países, que sejam obstáculos ao uso unilateral de poder. E que contribuam para uma ordem internacional legítima” (FONSECA JUNIOR, 1998a, p. 23). Assim, é através da ONU e das operações de paz que esses países buscam influenciar agendas e valores, além de contribuir para a garantia da ordem no sistema internacional.

Assim sendo, o artigo observará as participaçóes de maior destaque de cada país, além dos posicionamentos oficiais dos governos através, principalmente, dos seus respectivos documentos, buscando apontar os interesses dos mesmos nessas operaçóes. Assim, para fins de pesquisa, o método utilizado foi o estudo de caso, devido a individualidade de cada Estado, tendo uma sessão do trabalho dedicada a cada um isoladamente.

\section{Caso Canadense}

Para o Canadá, a definição de potência média significou um reconhecimento da sua imagem separada da ideia de "ex-colônia Britânica". A busca Canadense por essa posição é evidenciada após o fim da Segunda Guerra Mundial, principalmente durante as negociações da formação da ONU, em que o Estado demonstra vontade de reconhecimento pelos seus esforços na guerra e busca a capacidade de influência (HAYES, 1997). Na análise dos documentos de defesa Canadenses, percebe-se a inclusão da participação do país em operaçôes internacionais como um dos pontos para a garantia da sua segurança nacional. Apesar de mudar a ênfase no assunto ao longo dos anos, o país nunca deixou de participar completamente dessas ações, inclusive reconhecendo a importância dessa área para a concepção da sua identidade nacional e no exterior.

Nos primeiros documentos de defesa canadense encontram-se trechos definindo algumas açóes como características de uma potência média e as restriçóes que acompanham o termo, inclusive usando as limitaçôes econômicas ou militares como inerentes à essa condição, servindo de justificativa para não agir de determinadas formas. Apesar das limitaçôes, essa característica impulsionou o país, principalmente durante a Guerra Fria, na questáo das operações de paz (CANADA, 1964). Após esse momento, o país passa por diversos cortes na pasta de defesa, por causa de crises fiscais. Já em 2005, a política de defesa traz uma grande preocupação com a distribuição de poder no sistema internacional, reconhecendo que a emergência de novos atores com influência considerável, como Brasil, afeta o Canadá (CANADA, 2005). Seguindo essa linha de ação, no documento de 2008, o governo traz as forças armadas e a sua participação em operaçóes internacionais, novamente, como uma ferramenta para maior liderança no cenário internacional (CANADA, 2008).

Assim, o Canadá é envolvido nas operações de paz da ONU desde a operação decorrente da Crise de Suez, por causa da nacionalização do Canal de Suez pelo Egito, em 1956 (UNITED NATIONS ASSOCIATION IN CANADA, 2007). Por causa da sua localização estratégica, o canal era extremamente importante, principalmente, para países Europeus. Nessa situação, o governo Canadense defendeu a criação de uma força policial da organização para manter a paz no local. Apesar de condenar as açōes da Grã-Bretanha e da França, dando ultimatos aos países do Oriente médio, o país náo podia ser totalmente contra os países europeus, que eram seus principais aliados no continente. Assim, a organização de uma operação de paz dentro do âmbito da ONU foi uma forma de resolver esses problemas (WAGNER, 2007). Portanto, o país foi responsável pela formação da noção de operaçôes de paz, de acordo com o discurso na Assembleia Geral defendendo a criação da Força de Emergência no Egito, e da primeira grande operação armada em 1956, que foi comandada por um general Canadense. 
Em seu discurso na Assembleia, Pearson argumentou que as propostas atuais não foram longe o suficiente para lidar com as tensōes dentro do Suez. Em vez disso, Pearson acreditava que o que era necessário era "uma força policial e de paz verdadeiramente internacional ... grande o suficiente para manter essas fronteiras em paz enquanto um acordo político está sendo elaborado". Essa força de paz seria implantada para facilitar assentamentos a fim de trazer paz internacional e segurança (UNITED NATIONS ASSOCIATION IN CANADA, 2007, p.4-5, tradução nossa ${ }^{3}$ ).

Apesar do reconhecimento dessas operaçóes na identidade do país, um debate proeminente entre os especialistas da área é a ideia do "Mito da manutenção da paz canadense" (WAGNER, 2007, p.45, tradução nossa ${ }^{4}$. Ele ganha destaque no auge da expansão da missão do país no Afeganistão com uma polêmica sobre o papel pertinente das Forças Armadas e concentra-se, principalmente, na questão da "tradição histórica do Canadá de manutenção da paz e [n]o que os canadenses visualizam como açóes legítimas no cenário internacional" (WAGNER, 2007, p.45, tradução nossa ${ }^{5}$ ). O Mito consiste na ideia de que a participação do país nessas operaçóes, além de serem motivados pelo humanitarismo e pelo altruísmo, é a prioridade das Forças Armadas Canadenses (WAGNER, 2007). Em todas as menções sobre operações internacionais nos documentos canadenses, ficou claro que sua participação, apesar de serem rodeadas por um

3 "In his speech to the Assembly, Pearson argued that current proposals did not go far enough to deal with tensions within the Suez. Instead, Pearson believed that what was needed was 'a truly international peace andpolice force...large enough to keep these borders at peace while a political settlement is being worked out.' This peacekeeping force would be deployed to facilitate settlements in order to bring about international peace and security"

4 "Canadian peacekeeping myth"

5 "Canada's historical tradition of peacekeeping, and what Canadians visualize as legitimate action on the international stage" discurso de responsabilidade, eram políticas de influência e de garantia da segurança do país. Entretanto, "o público considera o Canadá como uma naçáo de manutenção da paz, ignorando seu passado de guerra e continuado envolvimento durante toda a Guerra Fria e no século XXI" (HILL, 2017, p.75, tradução nossa ${ }^{6}$.

Assim, um dos principais exemplos da atuação do Canadá que evidencia suas motivações além do discurso altruísta é sua presença na composição das Forças no Chipre. Tal operação ganhou grande importância no governo com o seu estabelecimento em 1964. Sendo a missão mais longa do país, a operação no Chipre, que é uma área estratégica para a OTAN, buscava controlar a relação deteriorada entre Gregos-cipriotas e Turcos-cipriotas. Ela foi uma iniciativa do Governo Canadense, tendo como ideia impedir que a organização ficasse fragilizada, pois uma falha no sistema de segurança coletiva afetaria a segurança do país, principalmente num momento em que a ameaça da União Soviética ainda era muito presente no ambiente. Levando em consideração que Grécia e Turquia eram aliadas da OTAN, o país buscava uma forma de resolver a situação sem que o arranjo de segurança fosse afetado (UNITED NATIONS ASSOCIATION IN CANADA, 2007).

Através da intervenção, o país impediu o conflito entre dois importantes aliados da OTAN numa área de posição estratégica para a aliança. Assim, "a missão de manutenção da paz liderada pelos canadenses ajudou a desarmar as tensóes, e ajudou a evitar uma divisão dispendiosa na aliança da OTAN" (WAGNER, 2007, p.53, tradução nos$\mathrm{sa}^{7}$ ). Essa operação também evidencia a mudança de

6 "the public considers Canada as a peacekeeping nation, ignoring its warfighting past and continued involvement throughout the Cold War and into the 21st century"

7 "The Canadian-led peacekeeping mission helped defuse tensions, and it helped prevent a costly split in the NATO alliance." 
percepção do governo, pois, principalmente com o fim da Guerra Fria e da ameaça da União Soviética, o conflito no Chipre, apesar de continuar sendo uma área estratégica, já náo apresentava tanto risco ao arranjo de segurança Canadense. Essa mudança de percepção associada a crises domésticas e novos focos de preocupação no ambiente internacional levaram a uma diminuição da participação do país.

Dessa forma, percebe-se que as operaçôes internacionais sempre foram destacadas nos documentos Canadenses como importantes para a garantia da sua soberania e segurança. De forma sutil, a participação e liderança nessas operaçóes foi uma forma de garantir um certo grau de influência no cenário internacional, corroborando seu status de potência média. Além disso, as operações serviam para garantir o contínuo funcionamento do seu arranjo de segurança coletiva. Entretanto, com o fim de uma ameaça proeminente e o aumento de pressóes domésticas, houve uma diminuição da participação nessas operaçôes. Com o surgimento do Terrorismo como uma ameaça e o reconhecimento de que novas potências médias estavam surgindo no sistema, botando em xeque sua posição de influência, há novamente uma busca pelas operaçôes internacionais, ao mesmo tempo em que o país lida com queda do orçamento destinado a questóes de defesa e a obsolescência de equipamentos das Forças Armadas.

\section{Caso Brasileiro}

O Brasil é presente em operações de paz desde os tempos de vigência da Liga das Naçóes, mesmo não sendo um dos Estados-membros. Sob a vigência da ONU, em 1947 o país compôs os observadores enviados à Comissão Especial das Naçôes Unidas para os Balcâs, contudo, sua primeira contribuição com tropas, per se, se deu na I Força de Emergência das Naçóes Unidas, em 1956 (NASSER, 2012).
Embora ainda tenha participado de missóes ao longo dos anos $1960^{8}$, o Brasil diagnosticou, nos anos 1970, que a Organização das Naçóes Unidas estaria a serviço de um congelamento de poder mundial (FONSECA JUNIOR, 1998b).

Gelson Fonseca Junior (1998b) descreveu este período como uma fase de "autonomia pela distância”. Em um contexto bipolar, no qual apenas dois extremos possíveis podiam ser adotados, mesmo não se identificando com o polo soviético, a diplomacia brasileira optou por buscar seus interesses a partir de um afastamento também do bloco ocidental, se posicionando de maneira crítica ao mesmo. Dentro da ONU, as principais características desta nova postura foram o afastamento brasileiro dos foros multilaterais, a aparente falta de interesse em disputar um assento permanente do Conselho de Segurança do organismo e esvaziando as operaçóes de paz.

Nos anos 1990, ainda dentro da percepção de Gelson Fonseca (1998b), o Brasil retornara a uma atividade mais evidente dentro da comunidade internacional por meio da "autonomia pela participaçáo", pautada nas possibilidades oferecidas pelas novas regras e instituiçóes previstas via Consenso de Washington (1989). Entrava em vigor uma inserção pautada nas diretrizes neoliberais, a partir da qual os países em desenvolvimento verteram para uma participação positiva dentro da agenda proposta pelas superpotências. Foi dentro do governo de Fernando Henrique Cardoso (1994-2002) que este novo posicionamento iniciado no governo Collor se consolidou.

De acordo com Raúl Bernal-Meza (2002), o Brasil, ao se reintegrar à comunidade internacional

\footnotetext{
$8 \mathrm{O}$ Brasil contribuiu com tropas para a Operação das Nações Unidas no Congo (UNOC), vigente entre julho de 1960 e junho de 1964., com o objetivo de garantir a retirada das tropas belgas do território congolês, provendo a assistência militar necessária ao país alvo da missão (ANDRADE; HAMANN; SOARES, 2019).
} 
de maneira plena, assumiu o papel de "potência média", tendo como uma das principais posturas a proposição de sua própria candidatura como membro permanente do Conselho de Segurança. Apesar de suas iniciativas regionais, passou a se aproximar de outras "potências médias" como China, Índia e Rússia. Com o objetivo de lograr seus objetivos,

(...) o único modo de aspirar a um reconhecimento como potência regional e como potência média mundial, a partir de sua condição de país-continente, fará necessariamente com que o país tenha que assumir posiçóes a respeito de diversos tópicos da agenda mundial, o que levará a um aumento significativo do perfil político da inserção internacional. (BERNAL-MEZA, 2002, p. 40).

As operaçóes de paz foram influenciadas por esta lógica. Desde 1989, houve um movimento não só de retorno, mas de um engajamento sem precedentes na história brasileira. Segundo Filipe Nasser (2012), desde o marco de 1988, o Brasil ocupou assento não permanente no Conselho de Segurança das Naçóes Unidas cinco vezes, sendo o maior ocupador da vaga, juntamente com o Japão. De fato, esta atividade passou a ser compreendida como um dos instrumentos para a consecução dos objetivos estratégicos brasileiros, sendo incorporada aos principais documentos de sua política de defesa. $\mathrm{O}$ primeiro destes foi a Política Nacional de Defesa (1996), que incluiu a participação em operaçôes de paz como uma das diretrizes de ação na busca pelos objetivos propostos anteriormente no mesmo documento, entre eles, "a projeção do Brasil no concerto de nações e sua maior inserção no processo decisório internacional" (BRASIL, 1996, p. 7).

Durante o governo Lula (2003-2010), que deu continuidade a essa busca por maior protagonismo nas relaçóes internacionais, outros quatro documentos apontaram para a consolidação da presença das operações de paz nas práticas internacionais brasileiras (OLIVEIRA, 2009). O primei- ro destes foi a reformulação, em 2005, da PND, a Política de Defesa Nacional (BRASIL, 2005). Em seguida, foram lançados em 2008 a Estratégia Nacional de Defesa (BRASIL, 2008a) e o Livro Branco de Defesa Nacional (BRASIL, 2008b), ambos prevendo ação conjunta com o Centro Conjunto de Operaçóes de Paz no Brasil para adestramento de militares e um engajamento cada vez maior nas missóes que se enquadrassem dentro das diretrizes da política externa brasileira. Por último, foi promulgado o Manual de Operaçóes de Paz (BRASIL, 2013), que fornece todas as informaçôes teóricas, técnicas e institucionais que envolvem o engajamento de qualquer força em tal atividade.

Segundo relatório produzido por Eduarda Passarelli Hamann (2015), o país tem participação em $70 \%$ das missóes já sancionadas pela ONU ao longo de sua história. A partir deste trabalho é concluído que o grau de comprometimento alcançado por esta potência média "alcançou tamanha envergadura que já não é possível voltar atrás sem grandes prejuízos para a organização do sistema internacional. E sem grandes prejuízos para a própria posição relativa do país na ordem global" (HAMANN, 2015 , p. 2). Entretanto, algumas operaçôes têm papel mais primordial, como a ação brasileira em Moçambique, que representou um novo posicionamento do país; a Missão das Naçôes Unidas para a Verificação de Angola; e no Líbano - onde exerce comando do componente naval.

Contudo, foi a ação no Haiti, sob amparo da Missão das Naçōes Unidas para Estabilização do Haiti (MINUSTAH), que marcou seu auge. Convidado para liderar o componente militar da missão em 2004, o Brasil permaneceu em solo haitiano por treze anos. Esta atuação foi marcada por um envio maciço de forças militares, mas por um envolvimento policial, financeiro, diplomático e político. Foi comum durante o período da missão o entendimento de que a mesma seria essencial para 
que o auge da política externa brasileira fosse alcançado: o assento permanente no Conselho de Segurança das Nações Unidas por meio da consecução de uma reforma estrutural na organizaçáo. Segundo Fontoura e Uziel (2017), o ano de 2004, início da MINUSTAH, estava inserido em um período de "reinvestimento" na ONU, especialmente por meio de operaçóes de paz.

A missão decorreu, a liderança do Brasil em termos de operação de paz foi consolidada, contudo o resultado em termos de ampliação da influência dentro das Nações Unidas não se consolidou. O status de poder dentro do Conselho de Segurança permaneceu o mesmo, e o tema relativo à sua reforma foi ofuscado na política exterior do primeiro mandato de Dilma Rousseff (CERVO; LESSA, 2014). A herança deixada pela expressiva participação brasileira na MINUSTAH foi, primeiramente, o país ter se tornado uma referência em termos de operaçóes de paz. O general Santos Cruz, por exemplo, após ser o force commander no Haiti entre setembro de 2006 e abril de 2009, foi indicado para assumir o mesmo posto no Congo. Outros oficiais assumiram durante o governo Temer e, especialmente, durante o governo Bolsonaro, cargos administrativos no Brasil.

\section{Considerações Finais}

Ao observar os casos Canadense e Brasileiro, notou-se que a participação desses países em operaçôes de paz no âmbito da ONU não se deu apenas pelos seus ideais humanitários e preocupações com áreas em conflito ao redor do mundo. Suas açôes também foram motivadas por interesses dos Estados. No Canadá, tem-se um forte discurso sobre "potência média" e a participação nessas açôes como uma forma de reafirmar essa posição no sistema internacional e garantindo a estabilidade internacional. No caso Brasileiro, nota-se o uso dessas operaçóes como uma forma de projeçáo internacional, formando uma imagem internacional positiva capaz de exercer influência dentro da organização.

Assim, entende-se que, para um entendimento aprofundado das operaçôes de paz, seus atores e motivos de existência, faz-se necessário um estudo voltado não apenas para o viés da organização, mas que olhe para os países que apoiam essas operaçôes e contribuem para as mesmas, tanto com financiamento quanto com recursos humanos. Dessa forma, percebe-se os objetivos de cada um que se relacionam nessa situação.

Apesar dos dois casos aqui apresentados serem de forte argumento para a afirmação de que interesses próprios movem os Estados em relação a essas operações, faz-se necessário que haja mais estudos nessa área, principalmente observando outros países que participam com frequência das mesmas, para melhor fundamentar essa vertente de análise.

\section{Referências}

ANDRADE, Israel de Oliveira; HAMANN, Eduarda Passarelli; SOARES, Matheus Augusto. A participaçáo do Brasil nas Operaçóes de Paz das Naçóes Unidas: Evoluçáo, Desafios e Oportunidades. 2442 Texto para Discussão. Brasília: IPEA. Jan, 2019. Disponível em: <http://www.ipea.gov.br/portal/ index.php?option=com_content\&view=article\&id=34557\&Itemid=444>. Acesso em: 20 maio 2019.

BERNAL-MEZA, Raúl. A política exterior do Brasil: 1990-2002. Revista Brasileira de Política Internacional, Brasília, v.45, n.1, p. 36-71, 2002. Disponível em: $<$ http://www.scielo.br/scielo.php?script=sci_arttext\&pi$\mathrm{d}=$ S0034-73292002000100002\&lng $=$ en $\& \mathrm{nrm}=$ iso $>$. Acesso em: 24 out. 2018.

BRASIL. Ministério da Defesa. Estratégia Nacional de Defesa. Brasília, 2008. Disponível em: <http://www.ecsbdefesa. com.br/defesa/fts/DN2008.pdf>. Acesso em: 20 maio 2019.

BRASIL. Ministério da Defesa. Livro Branco de Defesa Nacional. Brasília, 2008. Disponível em: <https://www.defesa.gov. br/arquivos/2012/mes07/lbdn.pdf>. Acesso em: 20 maio 2019. BRASIL. Ministério da Defesa. Manual de Operaçóes de Paz. Brasília, 2013. Disponível em: <https://www.defesa.gov. $\mathrm{br} /$ arquivos/File/doutrinamilitar/listadepublicacoesEMD/ md34_m_02_manual_op_paz_3ed_2013.pdf> . Acesso em: 20 out. 2018. 
BRASIL. Ministério da Defesa. Política de Defesa Nacional. Brasília, 2005. Disponível em: <http://www.ecsbdefesa.com. br/defesa/fts/DN2008.pdf>. Acesso em: 20 maio 2019.

CANADA. Department of National Defence. A Role of Pride and Influence in the World. Ottawa: 2005. Disponível em: <http://publications.gc.ca/collections/Collection/FR4-32005E.pdf>. Acesso em: 13 out. 2018.

CANADA. Department of National Defence. Canada First Defence Strategy. Ottawa: 2008. Disponível em: <http:// www.forces.gc.ca/assets/FORCES_Internet/docs/en/about/ CFDS-SDCD-eng.pdf>. Acesso em: 13 out. 2018.

CANADA. Department of National Defence. White Paper on Defense. Ottawa: 1964. Disponível em: <http://publications.gc.ca/collections/collection_2012/dn-nd/D3-6-1964eng.pdf>. Acesso em: 24 jan. 2019.

CERVO, Amado Luiz. LESSA; Antônio Carlos. O declínio: A inserção internacional do Brasil (2011-2014). Revista Brasileira de Política Internacional, Brasília, v. 57, n. 2, p. 133151, 2014. Disponível em: < http://www.redalyc.org/articulo. oa?id=35835782008>. Acesso em: 11 out. 2018.

FAGANELLO, Priscila Liane Fett. Operaçóes de Manutençáo da Paz da ONU: De que forma os Direitos Humanos Revolucionaram a principal ferramenta internacional da paz. Brasília: FUNAG, 2013.

FONSECA JUNIOR, Gelson. Brasil como potência média: possibilidades de ação internacional (Debate 1). In: SENNES, Ricardo (Ed.). Brasil e a Política Internacional. Santiago do Chile: FLACSO, p. 17-24, 1998a.

FONSECA JUNIOR., Gelson. A legitimidade e outras questóes internacionais. São Paulo: Paz e Terra, 1998b.

FONTOURA, Paulo Roberto C. T.; UZIEL, Eduardo. A MINUSTAH, o Brasil e o Conselho de Segurança das Naçôes Unidas. In: HAMANN, Eduarda Passarelli. TEIXEIRA, Carlos Augusto Ramires. A participaçáo do Brasil na MINUSTAH (2004-2017): percepçôes, liçôes e práticas relevantes para futuras missões. Rio de Janeiro: Instituto Igarapé e CCOPAB, p. 9-15, 2017. Disponível em: <https://igarape.org.br/ wp-content/uploads/2017/10/16-10-2017-web-AE-MINUSTAH-2017.pdf>. Acesso em: 22 out 2018.

HAMANN, Eduarda Passarelli. A Força de uma Trajetória: O Brasil e as operaçóes de paz da ONU (1948-2015). Rio de Janeiro: Instituto Igarapé, Nota Estratégica 19, 2015. Disponível em: <https://igarape.org.br/wp-content/uploads/2015/09/ NE-19_Brasil-e-opera\%C3\%A7\%C3\%B5es-de-paz-da-ONU-web.pdf> Acesso em: 22 out 2018.

HAYES, Geoffrey. Canada as a Middle Power: The Case of Peacekeeping. IN: COOPER, Andrew F. (Ed.). Niche diplomacy: middle powers after the Cold War. Reino Unido: Macmillan Press, p. 73-89, 1997.
HILL, Jamie Edward. Canadians and 'Peacekeeping': An Analysis of Canadian Understanding of Peacekeeping and Canada's involvement in peace support operations since 1991. 131 f. Dissertação (Mestrado em War Studies) - Royal Military College of Canada, Kingston, 2017. Disponível em <https://espace.rmc.ca/bitstream/11264/1261/1/CANADIANS\%20AND\%20PEACEKEEPING\%20-\%20AN\%20 ANALYSIS\%20OF\%20CANADIAN\%20UNDERSTANDING\%20OF\%20PEACEKEEPING\%20AND\%20CANADA \%E2\%80\%99S\%20INVOLVEMENT\%20IN\%20 PEACE\%20SUPPORT\%20OPERATIONS\%20SINCE\%20 1991\%20-\%20Hill.pdf> Acesso em: 15 out. 2018.

KEATING, Thomas F. Canada and World Order: The Multilateralist Tradition in Canadian Foreign Policy. Oxford: Oxford University Press, 2002.

NASSER, Filipe. Pax brasiliensis: projeção de poder e solidariedade na estratégia diplomática de participação brasileira em operações de paz da Organização das Nações Unidas. In: KENKEL, Kai Michael; MORAES, Rodrigo Fracalossi de (Org.). O Brasil e as Operaçóes de Paz em um mundo globalizado: Entre a tradição e a inovação. Brasília: IPEA, p. 213-242, 2012. OLIVEIRA, Eliezer Rizzo de. A Estratégia Nacional de Defesa e a Reorganizaçáo e Transformaçáo das Forças Armadas. Interesse Nacional. Abril/Junho 2009. Disponível em: <http:// www.resdal.org.ar/producciones-miembros/estrategia-nacional-defensa-eliezer-rizzo.pdf>. Acesso em: 20 maio 2019.

ORGANIZAÇÃO DAS NAÇÓES UNIDAS (ONU). Carta das Naçóes Unidas 1945. Disponível em: <http://unicrio.org. br/img/CartadaONU_VersoInternet.pdf >. Acesso em: 12 out. 2018.

TALIAFERRO, Jeffrey et. al. Neoclassical realist theory of International Politics. Oxford: OUP, 2016.

UNITED NATIONS ASSOCIATION IN CANADA. The Canadian Contribution to United Nations Peacekeeping. 2007. Disponível em: <http://unac.org/wp-content/uploads/2013/07/ CdnUNPkpgBooklet_e.pdf>. Acesso em: 18 out. 2018

UNITED NATIONS PEACEKEEPING. Departament of Peace Operations. 2018?. Disponível em: <https://peacekeeping.un.org/en/department-of-peace-operations $>$. Acesso em: 16 maio 2019.

WAGNER, Eric. The Peaceable Kingdom? The National Myth of Canadian Peacekeeping and the cold war. Canadian Military Journal, Kingston, p. 45-54, 2007. Disponível em: <http://www.journal.forces.gc.ca/vo7/no4/doc/wagner-eng. pdf>. Acesso em: 25 out. 2018

WOHLFORTH, William Curti. The Elusive Balance: Power and Perceptions during The Cold War. Cornell University Press, 1993. 